\title{
EMOTIONAL ABUSE AND NEGLECT
}

\author{
David H Skuse
}

Emotional abuse and neglect of children may take many forms from a lack of care for their physical needs, through a failure to provide consistent love and nurture, to overt hostility and rejection. Deleterious effects upon developing children are correspondingly diverse and tend to vary with age. In infancy neglect of physical care is likely to produce the most obvious consequences and developmental delays are also found. Preschool children may additionally present with disorders of social and emotional adjustment. Older children are likely to show behavioural problems at school, which are often accompanied by extensive learning difficulties. Emotional abuse is rarely the sole reason for seeking child protection through legal action, yet evidence is accumulating that its long term consequences upon social, emotional, and cognitive development may be far reaching and profound.

\section{Defining features}

Emotional abuse refers to the habitual verbal harassment of a child by disparagement, criticism, threat and ridicule, and the inversion of love; by verbal and non-verbal means rejection and withdrawal are substituted. Neglect comprises both a lack of physical caretaking and supervision and a failure to engage the developmental needs of the child in terms of cognitive stimulation. Although direct observation of parenting may raise suspicions about the presence of emotional abuse and neglect, the diagnosis is usually suggested by its consequences in the child: "the severe adverse

\section{Key features in infants}

Physical

Dr David H Skuse, MRCP, is Wellcome Trust senior lecturer in the academic department of child psychiatry at the Institute of Child Health, London.

The $\mathrm{ABC}$ of Clinical

Genetics will continue next week. The ninth article in this series, which has been edited by Professor Roy Meadow, will appear on 8 July. effect on the behaviour and emotional development of a child caused by persistent or severe emotional ill-treatment or rejection." All abuse entails some emotional ill treatment. There is often accompanying physical or sexual abuse. Without signs of physical or sexual maltreatment and disclosure of specific abusive activities, however, it is still possible to recognise characteristic groups of features that demand further investigation. Current knowledge on the subject does not yet allow us causally to link specific patterns of maltreatment to particular delays and disorders. In addition, the symptoms and signs to be described are not invariably indicative of abuse and neglect. But the cessation of abuse and its substitution with sensitive careoften in an alternative home - is usually followed by a rapid and dramatic improvement in developmental attainments, behaviour, and socioemotional adjustment.

\section{Infants}

Neglect of the physical and emotional nurture of an infant is likely to result in various signs and symptoms that should be fairly easily recognised. The aspects of physical development that are affected are those that demand the closest attention from caregivers. Babies are dependent creatures: they need to be fed regularly, to be kept in a reasonably dry and warm environment, and to have their bowel and bladder functions taken care of. If they are habitually cold and wet they will contract recurrent infections; if they do not have their nappies changed regularly they will develop nappy rash, which if neglected may cause scarring; if they are not fed adequately they will fail to thrive. Failure to thrive is usually defined as an exceptionally poor rate of growth in which weight (and often length) becomes increasingly divergent from normal age standardised values in the population. There are many reasons why such a pattern of growth may occur. Recent population surveys show that it is only exceptionally associated with abuse or deliberate neglect - even in non-organic cases. In families in which abuse is suspected other evidence to support those suspicions should be sought.

When there has been serious neglect social and psychomotor skills are also likely to be affected. If there has been no encouragement to acquire skills such as sitting, crawling, and walking the infant may show developmental delay. Infants are innately sociable: they enjoy interacting with others, adults or children. A severely neglected infant will not have learnt the joy of reciprocal 
smiling and laughter and so may not try to elicit attention. Although the concept of infant depression is controversial, increasing evidence suggests that the infants of some depressed (and therefore comparatively neglectful) mothers do show characteristic social responses, such as withdrawal, "looking away" behaviour, and emotional flattening. Severely understimulated infants may use self stimulatory behaviours such as persistently banging their head or rocking.

Selective attachments to important adults in an infant's life begin to be established around 6 to 8 months of age. A neglected or abused infant may show an unusual pattern of attachment. Usually the experience of consistent and sensitive parenting leads a child to feel safe and secure with the primary caregiver, even in the presence of a stranger. In an unfamiliar setting such as a surgery or clinic the wish to explore will be counterbalanced by a wish to stay close to the parent. Infants who have been abused or neglected lack this sense of security. They do not have sufficient confidence to explore their surroundings and seem ill at ease, whining, and unhappy and cling to their caregiver, who responds with irritation. Alternatively, there may be little evidence for any attachment behaviour and the infant either roams around the room in a completely non-directed fashion (attributable perhaps to high anxiety) or creeps quietly into a corner and observes the proceedings warily (frozen watchfulness). Recent research has shown, however, that large differences in the availability of and nurture by a caregiver do not always correlate with variations in attachment.

\section{Preschool children}

The physical consequences of persistent abuse and neglect through the preschool period often include poor growth not only in height and weight but also in the circumference of the head. Dramatic increases in head size have been documented when abused children have been removed to a nurturing alternative environment. Associated indicators of abuse include recurrent minor unexplained injuries, especially bruising. It is important to be aware of the distribution of bruises that is likely to indicate squeezing, choking, and slapping.

The development of communication between children, even those who cannot talk, and their caregivers is a subtle process with its own set of shared expectations and rules of operation. Persistent neglect and abuse will prevent the establishment of a "mutual faith in a shared world." Retardation in the development of receptive and expressive language will result, possibly exacerbated by recurrent inadequately treated middle ear infections and partial deafness. When the emotional abuse has been severe a child may become virtually mute. Language development seems to be especially vulnerable to the effects of a severely depriving environment.

The main indicators of emotional abuse and neglect of preschool children are usually behavioural. As long as the child does not mix in a social setting no problems may be reported. In a

\section{Key features in preschool children}

$\begin{array}{ll}\text { Physical } & \begin{array}{l}\text { Short stature } \\ \text { Microcephaly } \\ \text { Unkempt and dirty }\end{array} \\ \text { Development } & \begin{array}{l}\text { Language delayed } \\ \text { Attention span limited } \\ \text { Socioemotional immaturity }\end{array} \\ \text { Behaviour } & \begin{array}{l}\text { Overactive } \\ \text { Aggressive and impulsive } \\ \text { Indiscriminate friendliness } \\ \text { Seeks physical contact from } \\ \text { strangers }\end{array}\end{array}$

nursery school or day nursery, however, the child may show many and characteristic disorders. Attention span is commonly extremely limited: the child cannot settle to any task for more than a few seconds. This probably reflects a lack of attempts to engage the child's attention at home, but it may also indicate profound anxiety. Poor attention is often associated with excessive activity; such children may be described as hyperactive, although there is no evidence that most overactive preschool children have been abused. Aggressive disorders of conduct are an additional problem, and children who are observed persistently to hit or swear at their caregivers in the consulting room must be regarded as being at risk.

Peer relations will inevitably be problematic as persistently abused children do not develop sufficient social maturity to play cooperatively. Therefore their relations with other children may be characterised by a combination of aggression and withdrawal. Social relations will also be impaired by a lack of selective attachments; thus abused toddlers may show indiscriminately friendly behaviour that is qualitatively different from normal temperamental diversity and unlike behaviours reflective of broad social experience. Such children elicit intimate physical contact from complete strangers - they may end up on your lap within a few minutes of meeting - and seem to crave physical contact ("touch hunger"), even in the presence of their primary caregiver.

\section{School children}

In the child who has reached school age the effects of long term abuse and neglect occasionally lead to a characteristic syndrome of short stature coupled with certain behavioural and emotional problems. In many cases, however, there is no evidence of an effect on growth and the main indicators of abuse are to be found in poor social and emotional adjustment, behaviour problems, and learning difficulties.

School may be unable to compensate for the long term lack of cognitive stimulation at home because abused children have tremendous problems attending to learning tasks. The failure 
in concentration is often coupled with physical overactivity of such a degree that the child is regarded as disruptive and may be referred for assessment for special education.

Persistent denigration and rejection will inevitably cause a lowering of self esteem; children who feel they are worthless may carry a huge burden of guilt for their behaviour. They may seem depressed and persistently apologise for trivial or meaningless supposed misdemeanours. For example, an abused 5 year old seen recently at her first visit to a child guidance clinic apologised to the therapist for not having saved him a piece of her birthday cake; her birthday had been three months previously. Such a poor self image is not really compatible with forming and keeping friendships at school; the social skills needed to negotiate such relationships have never been learnt. Thus the emotionally abused child stands alone at playtime or is seen drifting around the periphery of small groups engaged in their own pursuits. Sometimes more able children develop a coping strategy whereby their main social interaction is with adults - that is, with teachers rather than pupils. They show a pseudomaturity that belies their lack of sense of self worth and their longing for affection and stability. When the abuse has been coupled with a style of interaction that is aggressive and threatening the child may show similar behaviour to pupils and teachers. Such behaviour may also be habitual because at home it is the only way of attracting attention.

In extreme cases of emotional abuse and neglect patterns of behaviour are so unusual or bizarre that they inevitably draw attention to the child. Self mutilation, from skin picking to deliberate self injury with knives or glass, is one. Repetitive rocking or other self stimulatory patterns of behaviour (including sexual ones) are others. Unusual patterns of defecation or urination are worrying in school children. Children who urinate or defecate in their clothes in class may be shunned as being smelly by their peers; perhaps that is how they view themselves - as disgusting and unpleasant individuals. Pools of urine or piles of faeces in the

\section{Key features in school children}

$\begin{array}{ll}\text { Physical } & \begin{array}{l}\text { Short stature } \\ \text { Poor hygiene } \\ \text { Unkempt appearance }\end{array} \\ \text { Development } & \begin{array}{l}\text { Learning difficulties } \\ \text { Lack of self esteem } \\ \text { Poor coping skills } \\ \text { Socioemotional immaturity }\end{array} \\ \text { Behaviour } \quad \begin{array}{l}\text { Disordered or few } \\ \text { relationships } \\ \text { Self stimulating or self } \\ \text { injurious behaviour, or } \\ \text { both } \\ \text { Unusual patterns of } \\ \text { defecation or urination, or } \\ \text { both }\end{array}\end{array}$

corridor or playground are signs that the culprit is urgently in need of assessment for possible abuse.

\section{Investigation and management}

Children who are being emotionally abused or neglected may not be in immediate physical or moral danger but their need for protection is not for all that diminished. It must be acknowledged, however, that there is limited scope in such cases for medical investigation without associated physical or sexual maltreatment. Doctors who suspect that a child is being abused should firstly seek the advice of a colleague who is experienced in such matters. If no local paediatrician or child psychiatrist is available an inquiry to a tertiary referral centre elsewhere in the county will often be met with a courteous and helpful response. Subsequently it will be necessary to share concerns with the statutory services responsible for child protection.

1 Department of Health and Social Security and the Welsh Office. Working together. A guide to arrangements for interagency co-operation for the protection of children from abuse. London: HMSO, 1988.

\section{MATERIA PARAMEDICA}

\section{Paddling the air: why do we swing our arms?}

It is curious that standard textbooks omit certain facts merely because they are self evident. I have previously pointed out that anatomy books make no mention of the fact that we have fingers. ${ }^{1}$ The same criticism may be levelled at textbooks of physiology and neurology. Why, for example, do we swing our arms when walking and running? The action is automatic and must surely be neurologically mediated. I do not accept the common "explanation" that its function is to aid balance, since one can walk with hands in trouser pockets without falling over; likewise, when carrying a heavy shopping bag in each hand. The "balance" theory probably arises from the sensation of awkwardness that occurs if one tries to inhibit the swinging of arms, when the hands are neither pocketed nor encumbered with shopping bags. Any such theory is, furthermore, teleological. That is to say, it suggests a purpose for the action, but fails to offer a neurological explanation.
Since the direction of swing is the reverse of that in the ipsilateral leg, the action would seem to be a vestige of our ancestral quadrupedal locomotion. There are some variations on this theme which may throw a little light on a dark area. The movement is no mere pendular swing. (Neither, for that matter, is that of a clock's pendulum, which receives a small maintaining impulse at the lowest point.) It is an active movement reflecting in its vigour that of the legs. Arm movements are violent in competitive sprinting. If one arm is prevented from swinging (for example, only one shopping bag) the free arm almost doubles the range of its swing. Which part of the brain tells it to do this? A patient in his middle 40s presented with early symptoms of parkinsonism affecting one arm. The initial symptom was a failure to swing that arm when marching during his days in the army. For this omission he was duly punished. - BERNARD J FREEDMAN 1 Freedman BJ. Fust a word, doctor. Oxford: Oxford University Press, 1987:69. 